\title{
DIPHTHERIA AMONG IMMUNIZED CHILDREN *
}

\author{
S. A. BLAUNER, M.D. \\ Adjunct Pediatrician, Lebanon Hospital; Medical Director, \\ Israel Orphan Asylum \\ NEW YORK
}

My object in reporting these cases is to have on record the fact that diphtheria can occur among children who possess either natural immunity or who have been immunized by the toxin-antitoxin procedure. If we are to utilize our knowledge of diphtheria immunity intelligently, without prejudice to the community or to the child who has suspicious sore throat, and raise the bars of precautions against a disease of so many possibilities, we must be sure that our interpretative value of a negative Schick reaction will stand the test of time and experience, and particularly that immunity, as obtained by the toxinantitoxin instillation, is sufficiently universal in its application that not even an occasional exception will alter its value. An immunity recorded by a negative Schick reaction should not be sufficient, and only when a sufficient number of Schick negative immunized children have been exposed to diphtheria contagion and have escaped the disease can a proper value be placed on it. An experience which I and my co-workers have had in a carefully supervised orphan asylum, ${ }^{1}$ has taught us that diphtheria in epidemic form can occur among immunized children, at least to say now that the value of a negative Schick reaction is not universal, and as a result further studies and clinical observations must be made before its exact value can be computed.

I am aware that these cases of diphtheria among immunized children are probably the first on record, at least where virulency test was taken, and, therefore, exception may be taken that our experience can be due to either faulty technic, imperfect toxin or antitoxin, or we are even dealing with an epidemic of septic sore throat in diphtheria carriers. All these possibilities have been considered and excluded and with the clinical picture and behavior of the cases there can be no other conclusion but that they were true cases of clinical diphtheria.

The children at the orphan asylum had all been given the Schick test, and our figures correspond so closely with the results of other investigators (40 per cent. positive and 60 per cent. negative) that no fault should be found with either technic or our material. The Schick positive children were all immunized by three doses of toxin-antitoxin,

* Read before the New York Physicians' Association, Oct. 28, 1920.

1. Israel Orphan Asylum. 
injected at intervals of one week, and after three months they were retested for immunity. A small group, however, still persisted with either a faintly positive or a strongly positive Schick reaction. The weakly positive cases were again tested after a lapse of several weeks, and the few that still reacted, together with the strong positive cases, were given an additional dose of toxin-antitoxin, the latter group receiving, however, a somewhat stronger dose than the three previous doses.

Table 1.-Findings with Schick Test in Sixty Cases

\begin{tabular}{|c|c|c|c|}
\hline 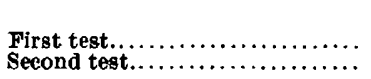 & $\begin{array}{l}\text { Reaction } \\
\text { Negative } \\
\text { Positive }\end{array}$ & $\begin{array}{c}\text { Number } \\
36 \\
24\end{array}$ & $\begin{array}{c}\text { Per Cent. } \\
60 \\
40\end{array}$ \\
\hline
\end{tabular}

Table 2 shows that two of the positive cases became negative fifteen months aften the $\mathrm{T}-\mathrm{A}$ injections.

TABLE 2.-Time of Toxin-Antitoxin Injection and Schick Control of the Twenty-Four Positive Cases

\begin{tabular}{|c|c|c|c|}
\hline 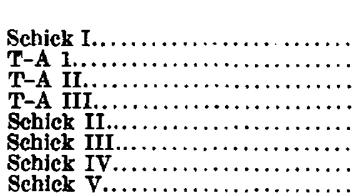 & $\begin{array}{c}\text { Date } \\
3 / 25 / 19 \\
4 / 18 / 19 \\
4 / 25 / 19 \\
5 / 2 / 19 \\
8 / 1 / 19 \\
12 / 20 / 19 \\
4 / 21 / 20 \\
8 / 19 / 20\end{array}$ & $\begin{array}{l}\text { 22 Cases } \\
\text { Positive } \\
\ldots \ldots \ldots \ldots \\
\ldots \ldots \ldots \ldots \\
\text { Negative } \\
\text { Negative } \\
\text { Negative } \\
\text { Negative }\end{array}$ & $\begin{array}{c}\text { 2 Cases } \\
\text { Positive } \\
\ldots \ldots \ldots \ldots \\
\ldots \ldots \ldots \ldots \\
\text { Positive } \\
\text { Positive } \\
\text { Positive } \\
\text { Negative }\end{array}$ \\
\hline
\end{tabular}

In this manner all our children were finally made Schick negative with the exception of two, who remained persistently positive even after additional tests. It is interesting to note, however, that in the last Schick test made on all the children, August, 1920, these two positive cases, after a lapse of fifteen months from the time the three toxinantitoxin immunizing injections were given, finally became Schick negative. The question naturally arises whether the toxin-antitoxin had any influence on this end result or whether it was due to the general tendency of natural immunity which the human organism acquires as it grows older. My own impression is that the toxin-antitoxin had no part in the Schick test results, for experience has shown that the toxinantitoxin shows its influence usually within from three to four months after its injection.

It is our practice to make throat cultures of all new admissions to the observation ward where they remain at least three weeks, depending, of course, on whether any contagion has appeared among them, and when finally admitted to the dormitories as permanent inmates, we are certain they are diphtheria-carrier free. As a further precaution, all 
permanent inmates are cultured at least once a year, sometimes oftener, depending on conditions, and as a result of this precaution, we feel that we are at all times free from diphtheria carriers.

Our food supply is regulated and under constant supervision to make sure that no contamination occurs; our milk supply, particularly, is thoroughly supervised and comes from a reputable dealer of this city. The children throughout the institution receive the same food and no outside food, particularly from friends and relatives who are allowed to visit but several times a year, is permitted, so that an infection, such as diphtheria or streptococcus sore throat, occurring from this source would be more or less evenly distributed throughout the institution and not confined to one dormitory as has occurred with this outbreak of diphtheria.

This outbreak of diphtheria was limited to one dormitory consisting of twenty-nine children. In all we had eight cases, beginning with three cases and spreading at intervals of from one to several days until eight children were ill (Table 3). Clinically, the appearance of the membrane, its location on tonsil and pharynx, moderate temperature, absence of toxic symptoms, which are usually present in a tonsillitis or a septic sore throat, gave the impression of a diphtheria throat, but as we had no suspicion that diphtheria can be possible in immunized children, antitoxin was not injected till the report as to the cultures was returned. When it became evident that we were probably dealing with diphtheria infection, we injected these three children, but waited with the prophylactic injections on the other children till we could test for the virulency ${ }^{2}$ of these positive cultures.

In the meantime, before the report of the virulency test was returned, the infection continued to spread at intervals of from twenty-four to forty-eight hours until we had a total of eight cases. Clinically, these additional cases showed diphtheritic throat, positive cultures and when the virulency test later returned positive we were sure that we were dealing with a positive Klebs-Loeffler infection. It is also interesting to note (Table 3, Schick III, 12/20/19, in Table 2) that given the Schick test and which showed results similar to those obtained on previous tests, thereby eliminating the possibility of some Schick negative reactions having turned to Schick positive. It is also interesting to note that four children possessed a natural immunity, and three children had an acquired immunity as the result of the antitoxin injection and one child was positive up to the time the infection occurred.

2. Cultures and virulence tests were made by the New York City Board of Health. Not only taken by department but under special supervision of head of department. 


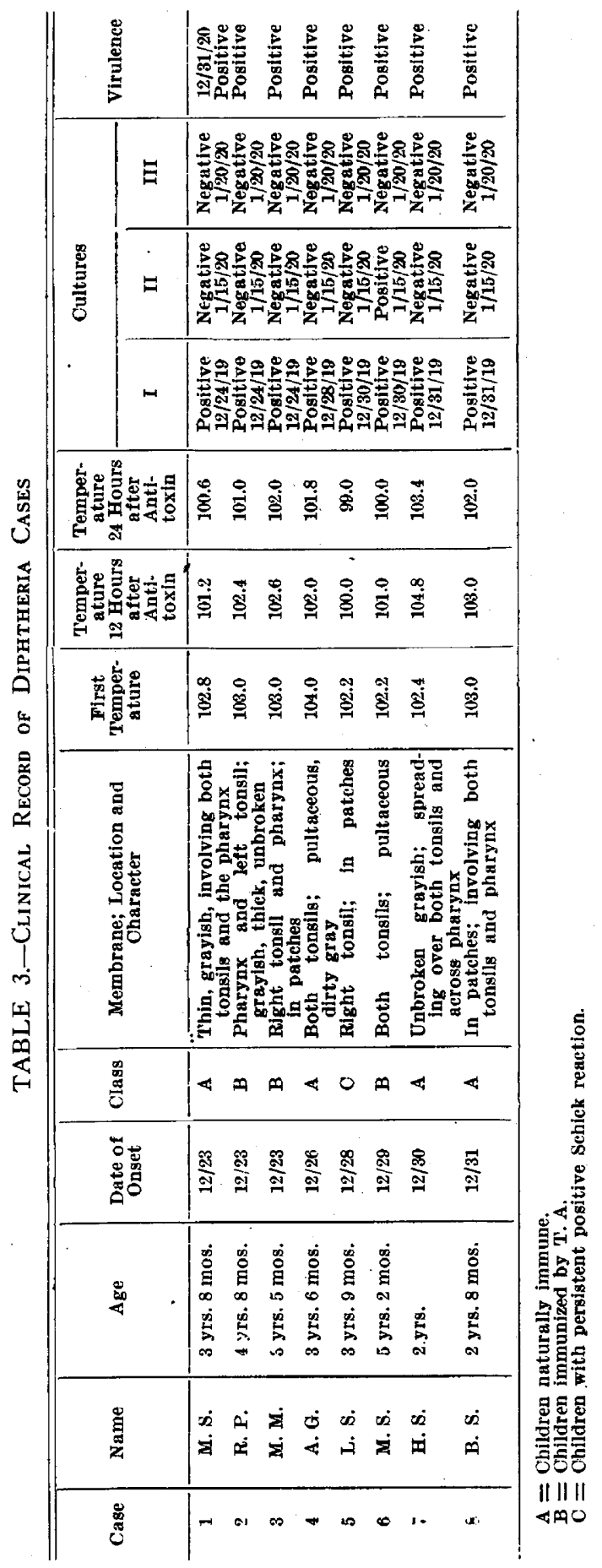


The main possibility to exclude in this epidemic is that these were cases of streptococcus sore throat in diphtheria carriers. It is difficult to understand, however, how we can include streptococcus sore throat, when we consider that all these cases occurred in one dormitory, with the supply of food the same throughout the institution. Furthermore, these children did not behave as children do who have a septic sore throat, neither was the appearance or location of the membrane, which was present in several cases on the pharynx as well, the same, nor was the intensity of the subjective symptom the same; and, what is most important, they all showed a virulent Klebs-Loeffler bacillus which disappeared a reasonable time after injection of antitoxin. We have here, then, I am sure, all clinical and laboratory evidence of a positive diphtheria infection.

\section{CONCLUSIONS}

In conclusion, permit me to reiterate that these eight cases are strong evidence that immunization is not absolutely proof against clinical diphtheria, and that we were dealing with a true Klebs-Loeffler infection for the following reasons: (1) character of the membrane, -dull gray, no surrounding hyperemia; (2) absence of prostration, -children were playful, while in septic sore throat infection the prostration is intense, out of all proportion to local involvement; (3) the disease was limited to one dormitory. In septic sore throat, food borne disease usually would have been more evenly distributed throughout the building; (4) occurrence of cases--gradually, from day to day. In septic sore throat, the onset would have been more or less simultaneous. (5) Positive virulent cultures were obtained in all cases which turned negative approximately two weeks after antitoxin injection; (6) absence of positive cases in other dormitories; (1) if these were merely persistent diphtheria carriers with no clinical reaction, it is fair to assume that some should remain so even after injection of antitoxin ; (8) immediate improvement of cases on receiving antitoxin; (9) immediate cessation of spread of the disease on administration of prophylactic doses of antitoxin to exposed children in the same dormitory. (10) Is it possible that streptococcus sore throat would have attacked only carriers and avoided the noncarriers?

I am indebted to Drs. Appel, Popper and Bloom for their kind cooperation and assistance in this work. 